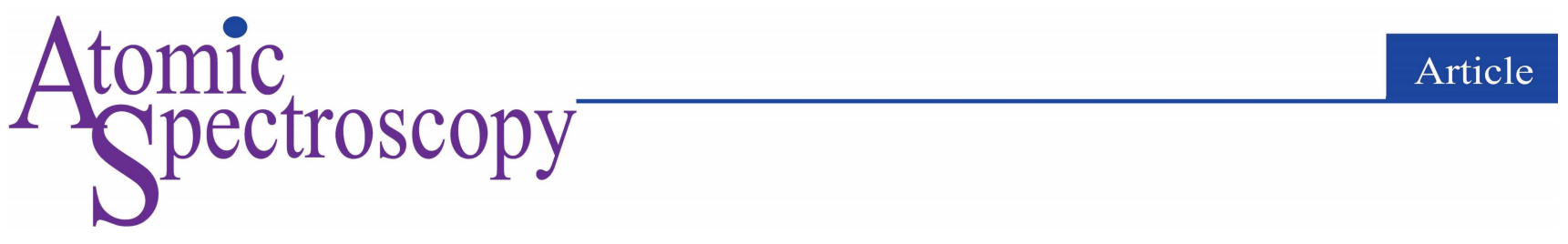

\title{
High-precision Measurement of Trace Level Na, K, P, S, Cr, and Ni in Lunar Glass Using Electron Probe Microanalysis
}

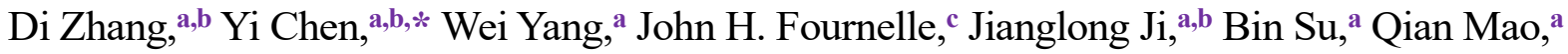

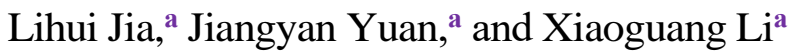 \\ ${ }^{a}$ State Key Laboratory of Lithospheric Evolution, Institute of Geology and Geophysics, Chinese Academy of Sciences, Beijing 100029, P.R. China

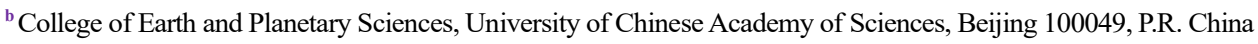 \\ ${ }^{c}$ Department of Geoscience, University of Wisconsin, Madison, WI 53706, USA
}

Received: October 01, 2021; Revised: January 18, 2022; Accepted: January 19, 2022; Available online: January $24,2022$.

DOI: $10.46770 / A S .2022 .001$

ABSTRACT: Lunar glass can provide critical information on the genesis of lunar rocks and the evolution of the Moon's interior. Several minor and trace elements in lunar glass, such as $\mathrm{Na}, \mathrm{K}, \mathrm{P}, \mathrm{S}, \mathrm{Cr}$, and $\mathrm{Ni}$, can be measured by electron probe microanalysis (EPMA) and are informative for understanding glass type, impact volatilization, and magmatic evolution processes. However, the analytical accuracy and precision of these trace-level elements in glass can be impeded by beam sensitivity, peak shift of X-ray and secondary fluorescence effects. Using EPMA, we constructed an optimized analytical method with high accuracy and precision to analyze trace elements simultaneously with major elements in lunar glass. The method was developed using the CAMECA SXFive EPMA at the Institute of Geology and Geophysics, Chinese Academy of Sciences (IGGCAS). The optimal analytical conditions for $\mathrm{Na}, \mathrm{K}, \mathrm{P}, \mathrm{S}, \mathrm{Cr}$, and $\mathrm{Ni}$ in lunar glass were as follows: $20 \mathrm{kV}$ accelerating voltage, $100 \mathrm{nA}$ beam current, 10 $\mu \mathrm{m}$ beam diameter, linear background mode, using large-area analytical crystals and aggregate counting strategy and a 10-min total counting time. Replicate analyses on basalt and komatiite glass standards show that the analytical results are consistent with the reference values. Variations in the levels of the analyzed trace elements fall within $\pm 10 \%$. The detection

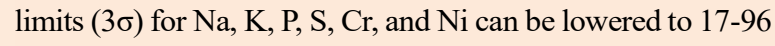
ppm. Our method can prohibit sample damage of lunar glass even after a 10-min analysis time. Therefore, this optimized method can provide precise trace and major element analysis of lunar glass and help to trace its origin.

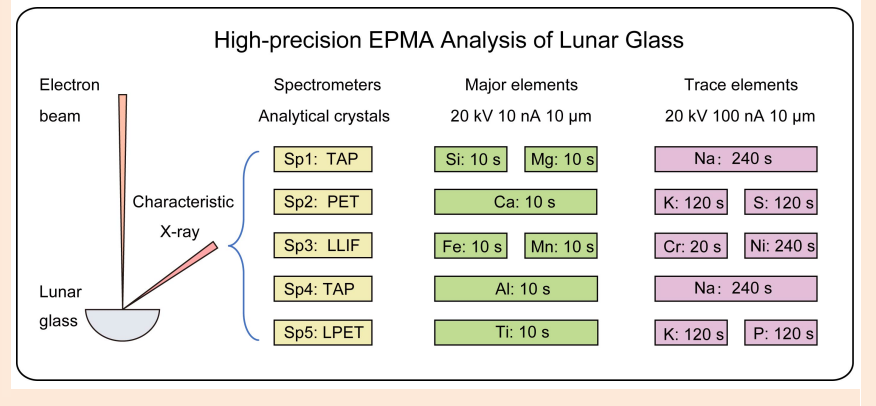

\section{INTRODUCTION}

Lunar glass is a major component of lunar samples and includes two types: volcanic glass and impact glass. ${ }^{1-3}$ Volcanic glass, formed in residual liquids at the end stages of crystallization of the lunar magma ocean, ${ }^{1,4,5}$ can provide critical information about the petrogenesis of mare basalts and the evolution of the Moon's interior. ${ }^{5-7}$ Impact glass, formed by melted impact ejecta, ${ }^{5,8}$ is used to investigate the composition of the source regions and to constrain the timing of impact events. ${ }^{9,10}$ Lunar glass mainly contains $\mathrm{Si}, \mathrm{Al}, \mathrm{Ca}, \mathrm{Mg}$, and $\mathrm{Fe}$, showing typical komatiitic or basaltic glass characteristics. ${ }^{2,11}$ Some minor/trace elements in lunar glass, such as $\mathrm{Na}, \mathrm{K}, \mathrm{P}, \mathrm{S}, \mathrm{Cr}$, and $\mathrm{Ni}$, play an important role in determining glass types, constraining the lunar origin, characterizing volatilization, and understanding the lunar magma evolution process. $\mathrm{Na}, \mathrm{K}, \mathrm{P}$, and $\mathrm{S}$ are important volatile elements and thus provide insights into volatilization during the impact process. ${ }^{2}$ The $\mathrm{Na} / \mathrm{K}$ ratio can help constrain the Moon's origin ${ }^{12,13}$ and the $\mathrm{Cr}$ and $\mathrm{Ni}$ contents in picritic glass can trace the magmatic evolution processes. ${ }^{5}$

The composition of lunar glass is commonly measured by modern microbeam tools with high spatial resolution, such as secondary ion mass spectrometry (SIMS), ${ }^{11}$ laser ablation inductively coupled plasma mass spectrometry (LA-ICP-MS), ${ }^{14}$ and EPMA. ${ }^{913}$ Although SIMS and LA-ICP-MS have much lower 
detection limits for trace elements, they are destructive for the precious lunar glass samples. In contrast, EPMA is undoubtedly nondestructive and capable of measuring the minor/trace $\mathrm{Na}, \mathrm{K}, \mathrm{P}$, $\mathrm{S}, \mathrm{Cr}$, and Ni contents in lunar glass. Considering the ready access of EPMA, its high spatial resolution, and its non-destructive nature, it is valuable to improve the analytical capability of EPMA for the determination of the low concentrations of $\mathrm{Na}, \mathrm{K}, \mathrm{P}, \mathrm{S}, \mathrm{Cr}$, and $\mathrm{Ni}$ in lunar glass.

EPMA has been used to study the major element compositions of lunar glass spheres since 1969 when the first Apollo 11 samples were returned. ${ }^{15}$ After that, many studies used electron probes to detect the compositional characteristics in lunar glass as more and more Apollo lunar samples were received. ${ }^{1,2,5,8,12,13}$ In addition, few studies also attempted to obtain trace elements in lunar glass by EPMA. Delano and Livi ${ }^{5}$ analyzed trace $\mathrm{Ni}$ in lunar glass with a high accelerating voltage of $30 \mathrm{kV}$ and a high beam current of $500 \mathrm{nA}$ using the count integration method. The detection limit of $\mathrm{Ni}$ was $\sim 22 \mathrm{ppm}$. Minor $\mathrm{P}$ contents were obtained at beam conditions of $20 \mathrm{kV}, 250 \mathrm{nA}$ by Delano. ${ }^{16}$ The reproducibility of replicate analyses for $\mathrm{P}$ in lunar glass is $\pm 20 \mathrm{ppm}$. Delano et al. ${ }^{17}$ detected $\mathrm{S}$ contents in picritic lunar glass by using $15 \mathrm{kV}$ accelerating voltage, $50 \mathrm{nA}$ beam current, and $300 \mathrm{~s}$ peak counting time, with a detection limit of $35 \mathrm{ppm}$. The detection limit of $\mathrm{Na}$ and $\mathrm{K}$ in lunar glass could be lowered to $\sim 30 \mathrm{ppm}$ after a $300 \mathrm{~s}$ electron beam bombardment at $15 \mathrm{kV}$ and $75 \mathrm{nA} \cdot{ }^{13,18}$ These studies indicate that lowering the detection limits of trace elements in lunar glass requires high accelerating voltages and beam currents, with long time bombardment.

However, the high-precision measurement of trace elements in lunar glass can be improved. Firstly, the beam sensitivity of lunar glass, which mainly includes the time-dependent-intensity (TDI) effect of alkali elements and sample damage under high electron beam conditions used for trace element analysis, ${ }^{19-24}$ has not been carefully evaluated. Meanwhile, avoiding unnecessary sample damage during EPMA is significant for these precious lunar samples. Decreasing the beam density (lowering accelerating voltage, beam current, and increasing beam diameter) can effectively reduce the TDI effect of $\mathrm{Na}, \mathrm{K}, \mathrm{Al}$ and $\mathrm{Si}$, and the sample damage in rhyolitic and hydrous glass. ${ }^{25-27}$ However, this approach would increase the detection limit and thus cannot accurately detect $\mathrm{Na}$ in lunar glass. In addition, the high beam diameter also limits the spatial resolution of EPMA. Thus, the optimal beam conditions for trace element analysis in lunar glass to overcome the TDI effect still require evaluation. Secondly, the $\mathrm{S}$ peak $(K \alpha)$ would shift as a function of valence state and glass composition. ${ }^{23,28}$ Inaccurate peak estimation of sulfur would cause analytical errors, especially for trace $\mathrm{S}$ in lunar glass. Lastly, trace $\mathrm{Na}, \mathrm{K}, \mathrm{P}, \mathrm{S}, \mathrm{Cr}$, and $\mathrm{Ni}$ in lunar glass cannot be processed simultaneously with major elements in a single run.
This study aims to examine spatial resolution, the TDI effect of $\mathrm{X}$-ray, and sample damage at various beam conditions in order to establish the optimal EPMA conditions for $\mathrm{Na}, \mathrm{K}, \mathrm{P}, \mathrm{S}, \mathrm{Cr}$, and Ni determination in lunar glass. Factors that influence $S$ peak position determination and $\mathrm{P}$ peak overlap are also discussed. In addition, the accuracy and precision of this method are evaluated based on the replicate analysis of well-characterized glass standards. Our method can be successfully applied to trace the origin of lunar glass.

\section{SAMPLES}

Lunar glasses are almost komatiite or basaltic in composition..$^{1-3,11}$ One komatiite glass (MPI-DING-GOR128, hereafter referred to GOR128) and one basaltic glass (VG-2, NMNH 111240-52), having similar compositions to lunar glass, were selected to monitor the accuracy and precision of EPMA analysis of lunar glass. The preferred values of the element composition of GOR128 glass were obtained from Jochum et al. ${ }^{29}$ The Na, K, P, $\mathrm{Cr}$, and Ni contents of the GOR128 glass standard are considerable ( $>100 \mathrm{ppm})$. However, the S content (4.3 ppm) is close to the lowest detection limit of EPMA. Therefore, we used this glass standard to monitor the accuracy and precision of $\mathrm{Na}, \mathrm{K}, \mathrm{P}, \mathrm{Cr}$, and $\mathrm{Ni}$ analysis in lunar glass, except for $\mathrm{S}$. The preferred values of the major elements of the VG-2 glass were obtained from Jarosewich et al..$^{30}$ and Helz et al. ${ }^{31}$. The S content of the VG-2 glass used here is recommended by D'Souza and Canil, ${ }^{32}$ which is broadly consistent with the values obtained by previous studies. ${ }^{33-35}$ The preferred compositional values of these glass standards are listed in Table 1.

NWA 13426 is a new lunar feldspathic regolith breccia meteorite found in 2020 in Northwest Africa. It is a typical breccia composed of various basaltic, feldspathic, and gabbro clasts. The impact melt regions observed in the matrix contain abundant glass

Table 1. Preferred compositional values of glass standards

\begin{tabular}{|c|c|c|c|c|}
\hline \multirow[b]{2}{*}{ Element } & \multicolumn{2}{|c|}{ GOR128 } & \multicolumn{2}{|c|}{ VG-2 } \\
\hline & wt \% & 2 stdev & wt\% & 2 stdev \\
\hline $\mathrm{SiO}_{2}$ & 46.1 & 0.4 & 50.81 & \\
\hline $\mathrm{TiO}_{2}$ & 0.288 & 0.012 & 1.85 & \\
\hline $\mathbf{A l}_{2} \mathbf{O}_{3}$ & 9.91 & 0.17 & 14.06 & \\
\hline $\mathrm{Cr}_{2} \mathrm{O}_{3}$ & 0.332 & 0.025 & - & \\
\hline MgO & 26.0 & 0.3 & 6.95 & \\
\hline $\mathrm{CaO}$ & 6.24 & 0.12 & 11.12 & \\
\hline $\mathrm{MnO}$ & 0.176 & 0.009 & 0.22 & \\
\hline $\mathrm{FeO}_{(\mathrm{t})}$ & 9.81 & 0.12 & 11.93 & \\
\hline $\mathrm{Na}_{2} \mathrm{O}$ & 0.574 & 0.026 & 2.62 & \\
\hline $\mathbf{K}_{2} \mathrm{O}$ & 0.036 & 0.005 & 0.19 & \\
\hline $\mathbf{P}_{2} \mathbf{O}_{5}$ & 0.025 & 0.005 & 0.2 & \\
\hline $\mathrm{SO}_{3}$ & - & & 0.349 & 0.043 \\
\hline $\mathrm{NiO}$ & 0.137 & 0.008 & - & \\
\hline Total & 99.63 & & 100.30 & \\
\hline
\end{tabular}



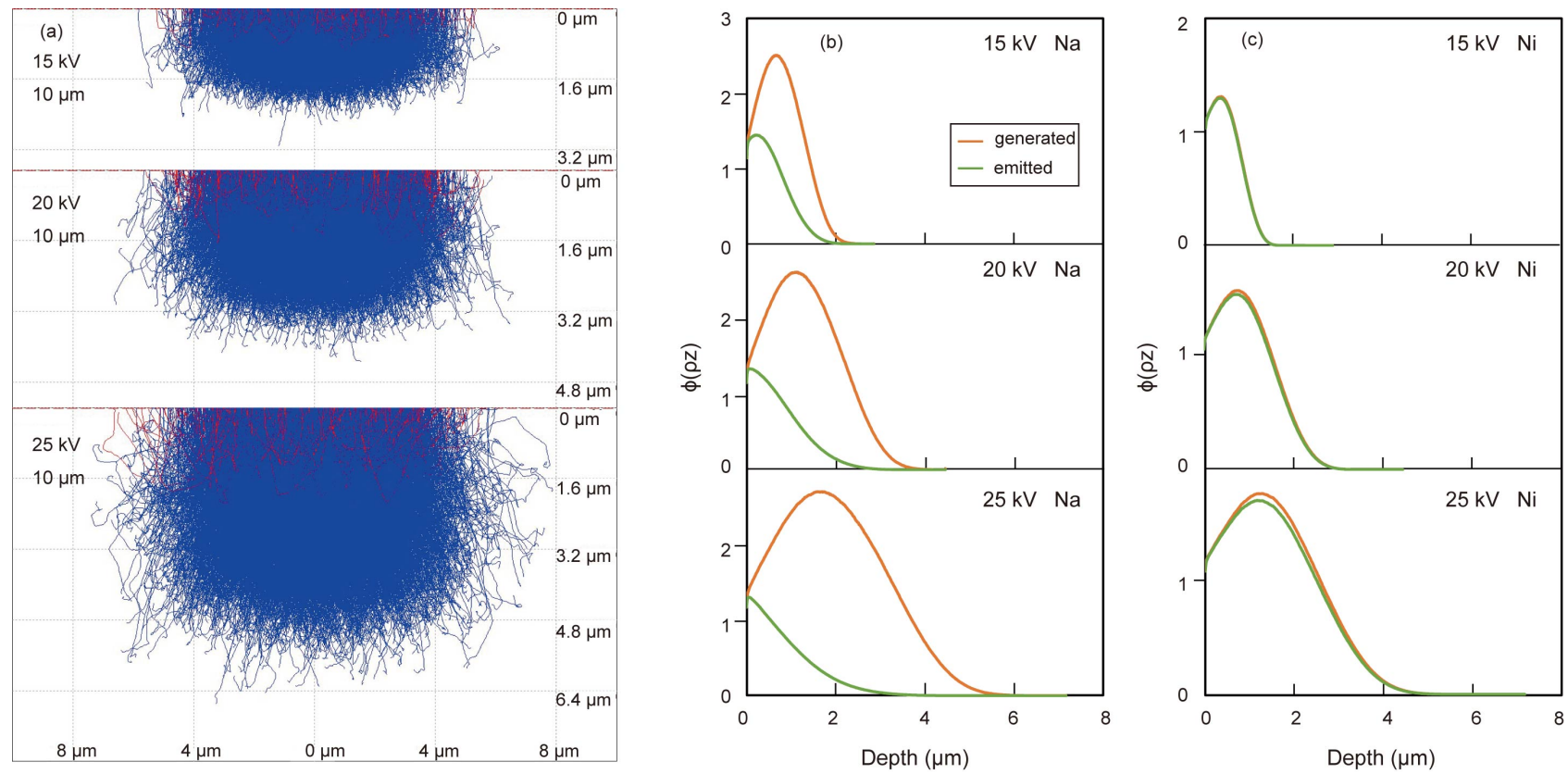

Fig. 1 (a) Monte Carlo simulations of electron scattering in GOR128 glass generated using Casino ${ }^{42}$ at accelerating voltages of 15, 20, and 25 kV (with a 10 $\mu \mathrm{m}$ beam diameter). Glass density is defined as $2.5 \mathrm{~g} / \mathrm{cm}^{3} .1 * 10^{6}$ electron trajectories were calculated. $1 * 10^{4}$ electron trajectories were used for displaying images. (b) Calculated $\phi(\rho z)$-curve for trace Na in GOR128 glass at accelerating voltages of 15, 20, and $25 \mathrm{kV}$. (c) Calculated $\phi(\rho z)$-curve for trace Ni in GOR128 glass at accelerating voltages of 15,20 , and $25 \mathrm{kV}$.

spheres. The minerals in NWA 13426 mainly include pyroxene, plagioclase, olivine, accessory troilite, chromite, Fe-Ni metal, silica, ilmenite, and U-rich baddeleyite and phosphates (Fig. S1). The glass spheres are randomly distributed in the sample, with sizes ranging from 20 to $200 \mu \mathrm{m}$. No zonation and inclusions can be found in the glass spheres (Fig. S1b).

\section{CHOICE OF ANALYTICAL CONDITIONS FOR TRACE ELEMENT ANALYSIS OF GLASS}

Accelerating voltage and spatial resolution. When setting up an EPMA procedure, the first-order decision is selecting the accelerating voltage. ${ }^{26}$ The accelerating voltage should preferably be at least twice the highest relevant excitation potential. ${ }^{36}$ In this study, $\mathrm{Ni}$ is the heaviest element to be analyzed using the $\mathrm{K \alpha}$ characteristic X-ray (Ec: $8.33 \mathrm{keV}, K \alpha: 7.47 \mathrm{keV}$ ). Therefore, 15 $\mathrm{kV}$, commonly used for routine analysis in most laboratories, ${ }^{13,21}$ is the minimum accelerating voltage. For most analyses, the peak intensities and peak-to-background ratios increase while increasing the accelerating voltages, ${ }^{36}$ except for light element analysis where severe absorption exists. ${ }^{37-39}$ Thus, lower detection limits and better statistical precision can be obtained by using a higher accelerating voltage. This is beneficial for trace element analysis, as proved by trace element measurements in olivine and quartz with detection limits below 10 ppm. ${ }^{19,22,40}$
However, higher accelerating voltage may cause lower spatial resolution. ${ }^{36}$ Incident electrons spread out in a zigzag path inside the sample (until they come to rest or are backscattered from the surface), forming an electron interaction volume. The size of the electron interaction volume is a function of material composition and accelerating voltage. ${ }^{41}$ It is worth noting that the depth of the interaction area is mainly controlled by the accelerating voltage for a given material, as it defines the energy of electrons and, therefore, how far into the sample the electrons travel and where X-rays can be generated. The Monte-Carlo simulations ${ }^{42}$ provide a straightforward method of estimating sampling depths and excited volumes for different elements in a certain phase. ${ }^{24}$ To select an appropriate accelerating voltage for lunar glass, we carried out the Monte-Carlo simulations for the $K \alpha$ characteristic X-ray signals of trace elements in the GOR128 glass at 15,20 , and $25 \mathrm{kV}$, respectively, with a defocused electron beam condition of $10 \mu \mathrm{m}$.

As shown in Fig. 1, the size of the electron interaction area increases while using a higher accelerating voltage. The depths of the interaction area (blue part) at 15,20 , and $25 \mathrm{kV}$ are $\sim 2.4, \sim 4$, and $\sim 6.4 \mu \mathrm{m}$, respectively (Fig. 1a). In addition, the depths and sizes of the lateral spread area of the emitted X-rays increase with higher accelerating voltage, which would reduce the spatial resolution. At $15 \mathrm{kV}$, most of the $\mathrm{Na} K \alpha$ and $\mathrm{Ni} K \alpha \mathrm{X}$-rays are emitted from sample depths of $2 \mu \mathrm{m}$ and $1.8 \mu \mathrm{m}$, respectively (Fig. $1 \mathrm{~b}$ and $1 \mathrm{c}$ ). However, by increasing the accelerating voltage to 25 $\mathrm{kV}$, most $\mathrm{Na}$ and Ni $K \alpha \mathrm{X}$-rays are emitted from sample depths of 
$4 \mu \mathrm{m}$ and $5 \mu \mathrm{m}$, respectively. On the other hand, a lower accelerating voltage would give a higher detection limit. We selected $20 \mathrm{kV}$ as the most appropriate accelerating voltage to balance the spatial resolution and the detection limit.

Beam sensitivity. Many geological materials, such as carbonates, ${ }^{43,44}$ phosphates, ${ }^{35,45}$ hydrous minerals, ${ }^{20}$ and glasses, ${ }^{25,26,46-48}$ are sensitive to beam current irradiation, leading to TDI variations of elemental X-rays and/or sample damage in these materials.

Previous studies show that the TDI effects and/or sample damages can be offset by decreasing the beam current, increasing the beam diameter, ${ }^{25,26}$ using a metal coating, ${ }^{49,50}$ TDI corrections, ${ }^{51}$ and cooling the samples.${ }^{51,52}$ However, trace Na, K, $\mathrm{P}, \mathrm{S}, \mathrm{Cr}$, and $\mathrm{Ni}$ in lunar glass is commonly less than $100 \mathrm{ppm},{ }^{1-3}$ requiring a high beam current and a long counting time to decrease the detection limit. Therefore, this study evaluated the effects of beam sizes and currents on beam sensitivity (mainly the TDI changes of $\mathrm{Na}$ and $\mathrm{K}$ as well as the sample damage) at $20 \mathrm{kV}$ for GOR128 glass.

All analyses were conducted using a CAMECA SXFive electron probe microanalyzer at the IGGCAS, which has a tungsten source gun, and is equipped with five spectrometers, and uses PeakSight software. Two beam current conditions at constant accelerating voltage can be utilized in one analytical setting. A lower beam current $(10 \mathrm{nA}$ with a beam diameter of $10 \mu \mathrm{m}$ in this study) can be used to analyze the major elements, while a higher beam current can be used for trace element analysis. The reference standards were coated with $20 \mathrm{~nm}$ carbon using a Leica EM ACE600 coater system, which could continuously monitor carbon thickness by using a quartz plate.

The Recorder utility of PeakSight software was used to record the changes of the elements' signals over 10-min durations in increments of $\sim 3$ seconds. The beam diameters were checked by optical inspection of the beam on a cathodoluminescent standard $(\mathrm{NaCl})$ before and after irradiation. Secondary electron (SE) images, backscattered electron (BSE) images, and reflected light images were taken to check sample damage after 10-min electron beam bombardments. Since $\mathrm{Na}$ and $\mathrm{K}$ are easier to migrate in glass, we detected the X-ray intensities of $\mathrm{Na}(K \alpha, \mathrm{TAP})$ and $\mathrm{K}(K \alpha$, LPET) under various beam conditions at $20 \mathrm{kV}$ for the GOR128 glass standard. After that, we investigated the X-ray intensities of other elements (P, S, Cr, and Ni) of the GOR128 glass standard at the optimal beam conditions. The X-ray intensities of $\mathrm{Na}, \mathrm{K}, \mathrm{P}, \mathrm{S}$, $\mathrm{Cr}$, and $\mathrm{Ni}$ were also investigated for lunar glass spheres of NWA13426 at the optimal beam conditions.

Effect of beam sizes on the TDI variation of elemental X-ray and sample damage. To evaluate the TDI effect and sample damage caused by the electron beam size, we investigated the Xray variations of $\mathrm{Na}(K \alpha)$ and $\mathrm{K}(K \alpha)$ at a $20 \mathrm{kV}$ accelerating voltage and a $100 \mathrm{nA}$ beam current with different beam diameters
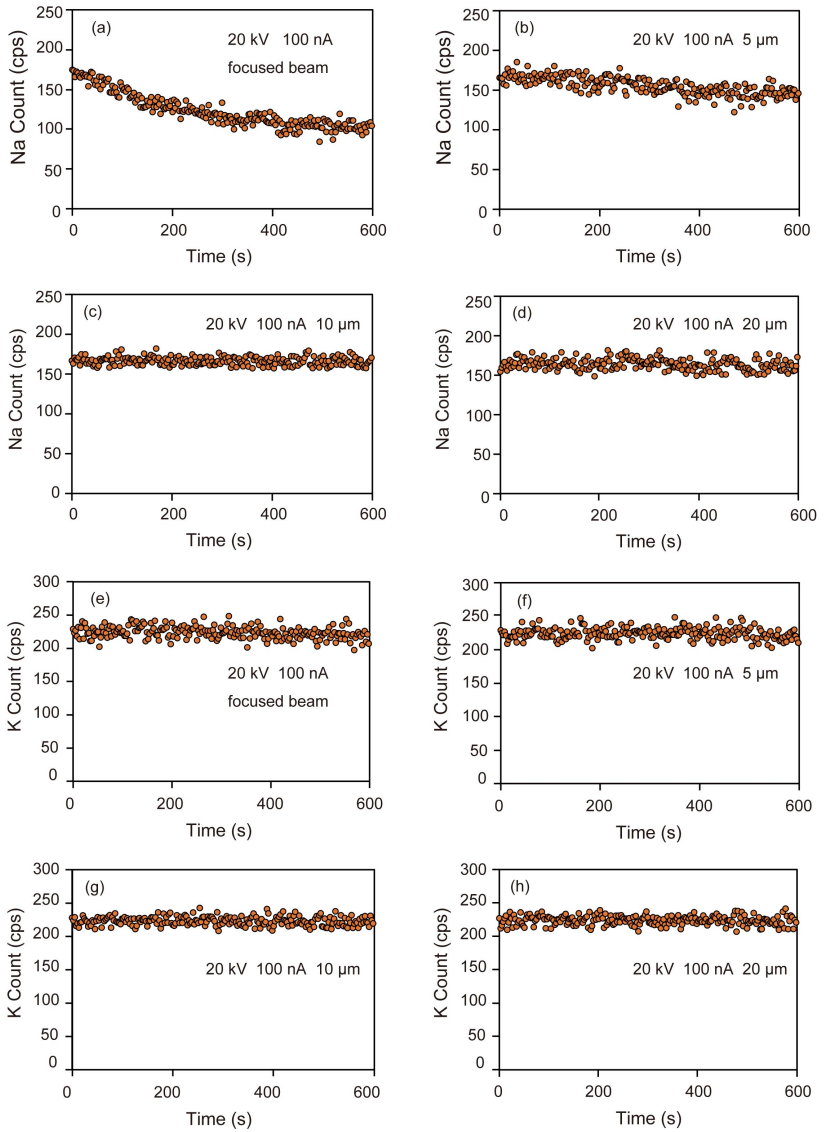

Fig. 2 Count rates (average, $\mathrm{N}=5$ ) for $\mathrm{Na}(\mathrm{a}-\mathrm{d})$ and $\mathrm{K}(\mathrm{e}-\mathrm{h})$ for the GOR128 glass standard over periods of $600 \mathrm{~s}$ measured with a focused beam and with beam diameters of 5,10 , and $20 \mu \mathrm{m}$ at $20 \mathrm{kV}, 100 \mathrm{nA}$.

(a focused beam, 5, 10 and $20 \mu \mathrm{m}$ ). Representative results are shown in Fig. 2 and the sample damages after 10-min electron bombardments are shown in Fig. 3.

$\mathrm{Na}$ and $\mathrm{K}$ exhibit different behaviors under various beam sizes. When a focused beam is used, the intensities of $\mathrm{Na} K \alpha \mathrm{X}$-ray decrease (nearly $50 \%$ loss, Fig. 2a), while the intensities of $\mathrm{K} K \alpha$ $\mathrm{X}$-ray remain steady (Fig. 2e). When the beam diameter increases to $5 \mu \mathrm{m}$, the $\mathrm{Na} X$-ray intensities drop slightly, whereas the $\mathrm{K} X$ ray intensities do not show clear variations (Fig. $2 b$ and $2 f$ ). For beam diameters of 10 and $20 \mu \mathrm{m}$, the X-ray intensities of $\mathrm{Na}$ and K remain stable (Fig. 2c-2d, 2g-2h).

Surface morphology characteristics can display visual effects after irradiation. Sample damage can be observed at the focused beam after a 10-min electron irradiation (Fig. 3a-3c). The bombardment area can be burned by the electron beam due to its high-power density, which can heat the samples locally since the fraction of the energy in the incident electron beam mostly converts into heat in the target. ${ }^{36}$ Increasing the beam diameter can minimize this heating effect under constant accelerating voltage and beam current (Fig. 3a-c). When the beam diameter is increased 

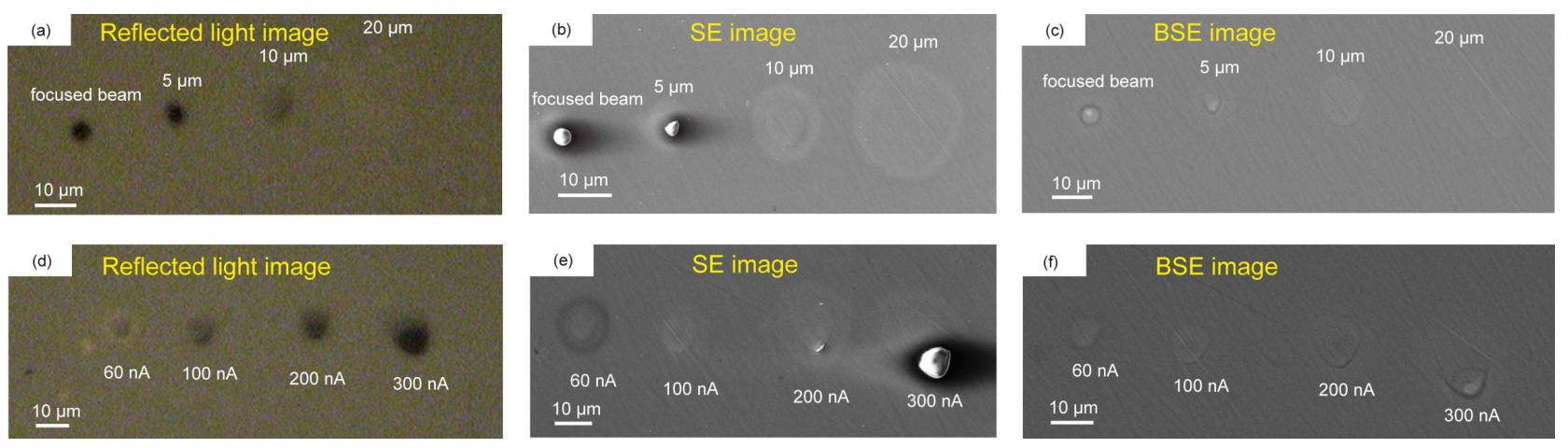

Fig. 3 Reflected light image (a), SE image (b) and BSE image (c) of GOR128 glass standard after 10 min irradiation with various beam sizes (beam condition: $20 \mathrm{kV}$ accelerating voltage, $100 \mathrm{nA}$ beam current). Reflected light image (d), SE image (e) and BSE image (f) of GOR128 glass standard after 10-min irradiation with various beam currents (beam condition: $20 \mathrm{kV}$ accelerating voltage, $10 \mu \mathrm{m}$ beam diameter).
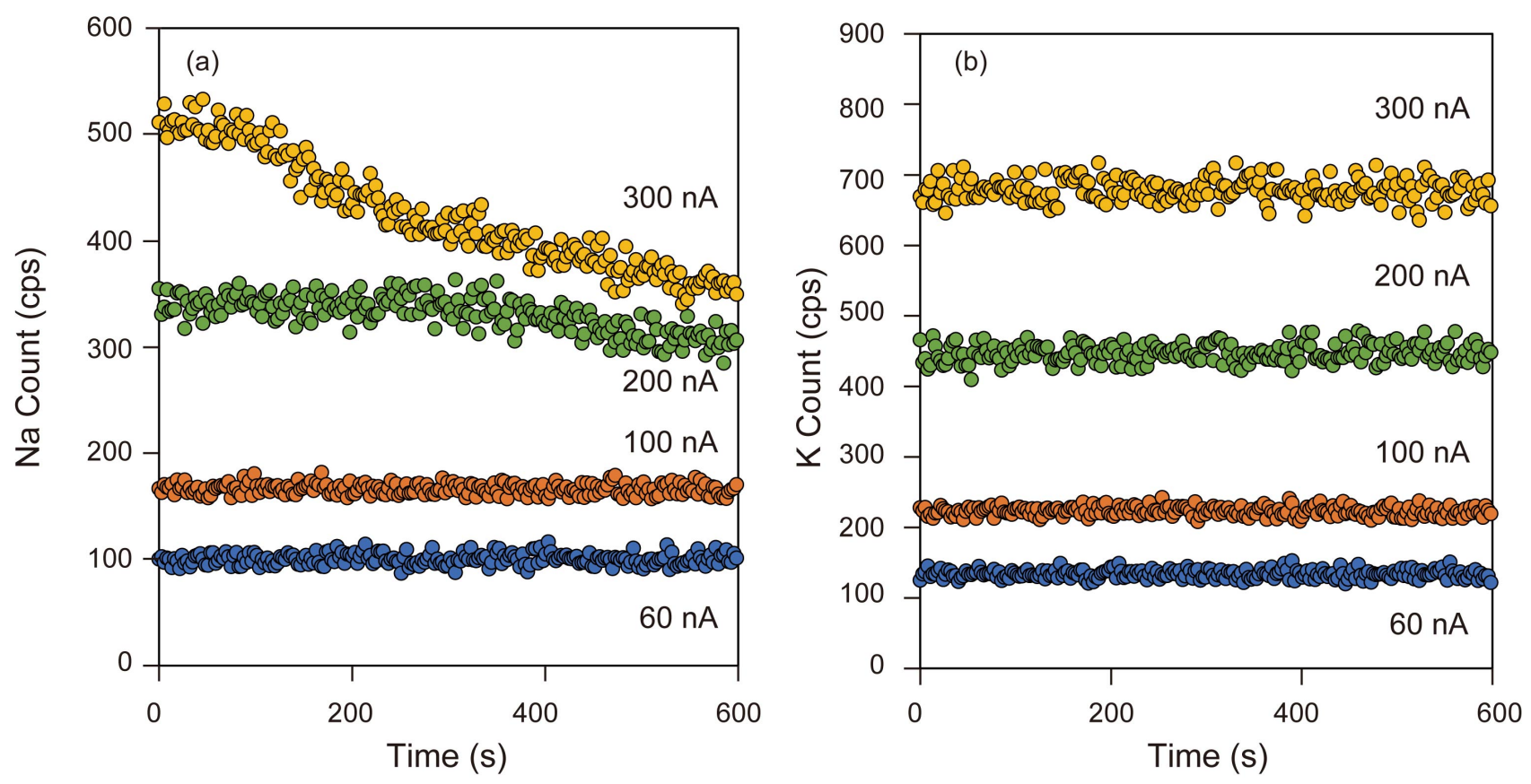

Fig. 4 Count rates (average, $\mathrm{N}=5$ ) for $\mathrm{Na}$ (a) and $\mathrm{K}$ (b) for the GOR128 glass standard over $600 \mathrm{~s}$ measurements with various beam currents of 60, 100, 200, and $300 \mathrm{nA}$ (accelerating voltage: $20 \mathrm{kV}$, beam diameter: $10 \mu \mathrm{m}$ ).

to 10 and $20 \mu \mathrm{m}$, no clear sample damage can be observed in all reflected light (Fig. 3a), SE (Fig. 3b) and the BSE (Fig. 3c) images. Only carbon contamination can be observed when using 10 and $20 \mu \mathrm{m}$ beam spot size. Considering elemental X-ray TDI effects, sample damages, and spatial resolution, $10 \mu \mathrm{m}$ is the best beam size for the GOR128 glass standard at $20 \mathrm{kV}, 100 \mathrm{nA}$.

\section{Effect of beam currents on the TDI variation of elemental X-}

ray and sample damage. To evaluate the influence of beam currents on the TDI effects and sample damage, we investigated the X-ray variations of $\mathrm{Na}(K \alpha)$ and $\mathrm{K}(K \alpha)$ at $60,100,200$, and $300 \mathrm{nA}$, respectively, with a $20 \mathrm{kV}$ accelerating voltage and $10 \mu \mathrm{m}$ beam diameter. As shown in Fig. 4a, the X-ray intensities of $\mathrm{Na}$ and $\mathrm{K}$ remain stable under 10-min irradiation, even the beam currents up to $100 \mathrm{nA}$. However, at $200 \mathrm{nA}$, the X-ray intensities of Na decrease slightly within $10 \mathrm{~min}$. At $300 \mathrm{nA}$, the Na X-ray intensities drop obviously (nearly $30 \%$ loss, Fig. $4 a$ ). In contrast, the X-ray intensities of $\mathrm{K}$ remain stable at 200 and $300 \mathrm{nA}$ (Fig. $4 b)$. This indicates that $\mathrm{K}$ in komatiite glass may not migrate at high beam currents with large beam sizes. No clear sample damage was found after a 10-min electron beam irradiation under 60 and 100 nA conditions (Fig. 3d-3f). However, surface sample damage was observed when increasing the beam currents to 200 and $300 \mathrm{nA}$ (Fig. 3d-3f). Based on the above results, the beam current of $100 \mathrm{nA}$ is the optimal choice at the given beam conditions.

The elements $\mathrm{P}, \mathrm{S}, \mathrm{Cr}$, and $\mathrm{Ni}$ are not easy to migrate in glass under electron beam irradiation. ${ }^{36}$ The count test in this study also supports this conclusion (Fig. 5a and 5b). No X-ray intensity 

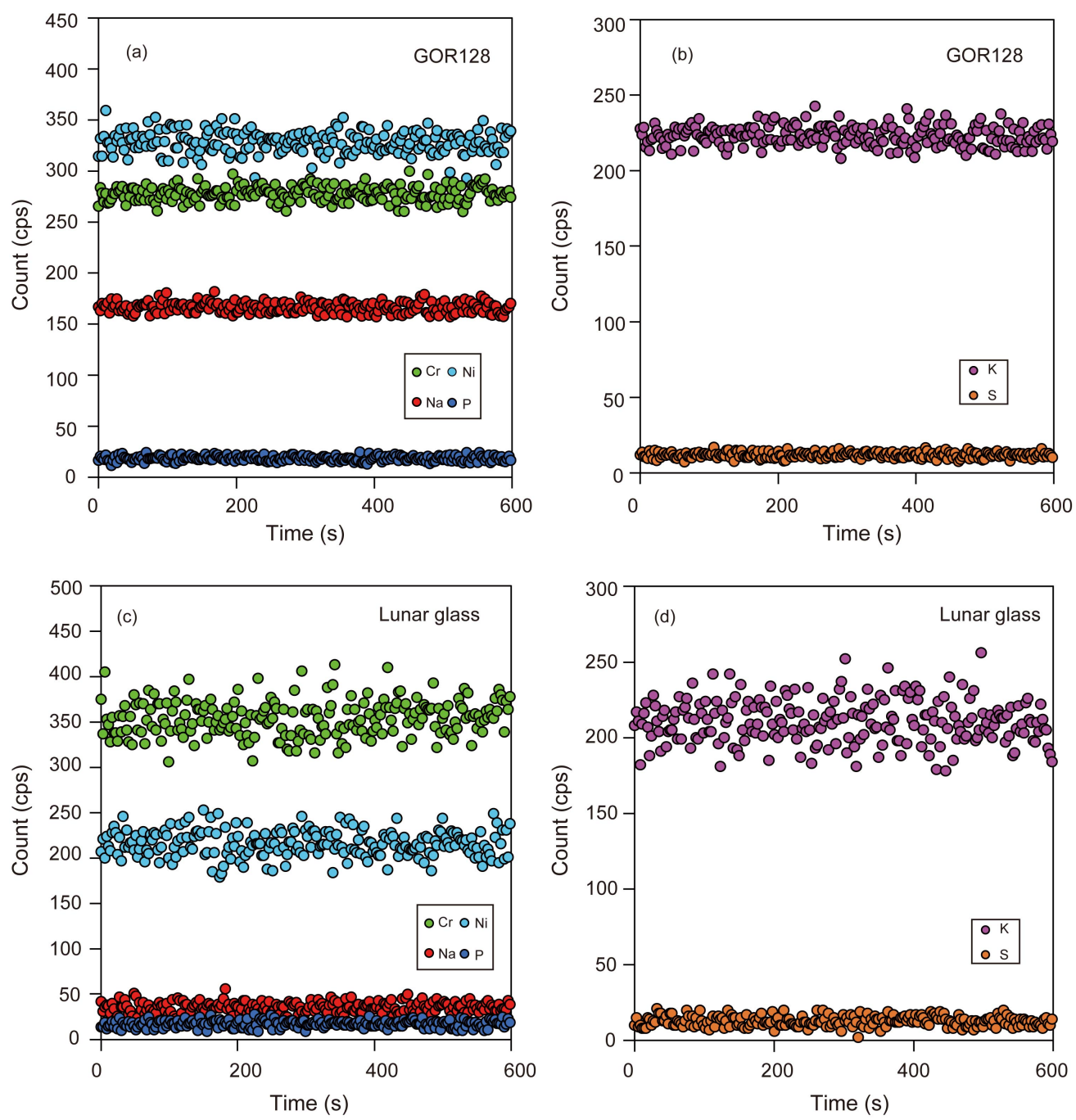

Fig. 5 Count rates (average, $\mathrm{N}=5$ ) for $\mathrm{Na}, \mathrm{K}, \mathrm{P}, \mathrm{S}, \mathrm{Cr}$ and $\mathrm{Ni}(\mathrm{a}$ and $\mathrm{b}$ ) for the GOR128 glass standard over periods of $600 \mathrm{~s}$ measured at the optimal beam condition (accelerating voltage: $20 \mathrm{kV}$, beam current: $100 \mathrm{nA}$, beam diameter: $10 \mu \mathrm{m}$ ). Count rates for the trace elements of interest (c and d) for the lunar glass sphere over periods of $600 \mathrm{~s}$ measured at the optimal beam condition (accelerating voltage: $20 \mathrm{kV}$, beam current: $100 \mathrm{nA}$, beam diameter: $10 \mu \mathrm{m}$ ).

variation of these elements could be observed at 10-min electron beam irradiation at the optimal beam conditions. Therefore, we suggest that the beam condition of $20 \mathrm{kV}, 100 \mathrm{nA}, 10 \mu \mathrm{m}$ is the most suitable choice for trace element analysis in the GOR128 glass standard.

Testing the TDI variation of elemental $X$-ray and sample damage at the optimal beam conditions for lunar glass. To test the feasibility of the above-mentioned optimal beam conditions in lunar glass, we also studied the X-ray intensity variations for the elements of interest of the glass spheres in the lunar breccia meteorite NWA 13426. As shown in Fig. 5c and 5d, all X-ray intensities of the detected elements remained steady at 10-min irradiation. No sample damage was observed after 10-min irradiation (Fig. 6). These results suggest that the optimal beam conditions obtained for the GOR128 glass standard also would work for lunar glass.
Peak and background. Precise peak intensity measurements are crucial for elemental analysis by EPMA. The net intensity is determined by measuring the peak X-ray line intensity (in cps/nA) and subtracting the background intensity. For major elements, peak-to-background ratios typically fall within the range of tens to hundreds, and background precision does not contribute significantly to overall measurement error values. ${ }^{53}$ However, this is not the case for trace elemental analyses where peak/background ratios approach unity due to their low concentrations. As the peak intensity level decreases, inappropriate background determination would increase analytical error. Since classical linear interpolation of background measurements on each side of the peak is commonly used in CAMECA software, it is crucial to exclude any potential interference on the peak and the background. ${ }^{19}$ We performed high-sensitivity wavelength scans on each side of the peak for $\mathrm{Na}$, $\mathrm{K}, \mathrm{P}, \mathrm{S}, \mathrm{Cr}$, and Ni using glass standards to identify accurate peak 

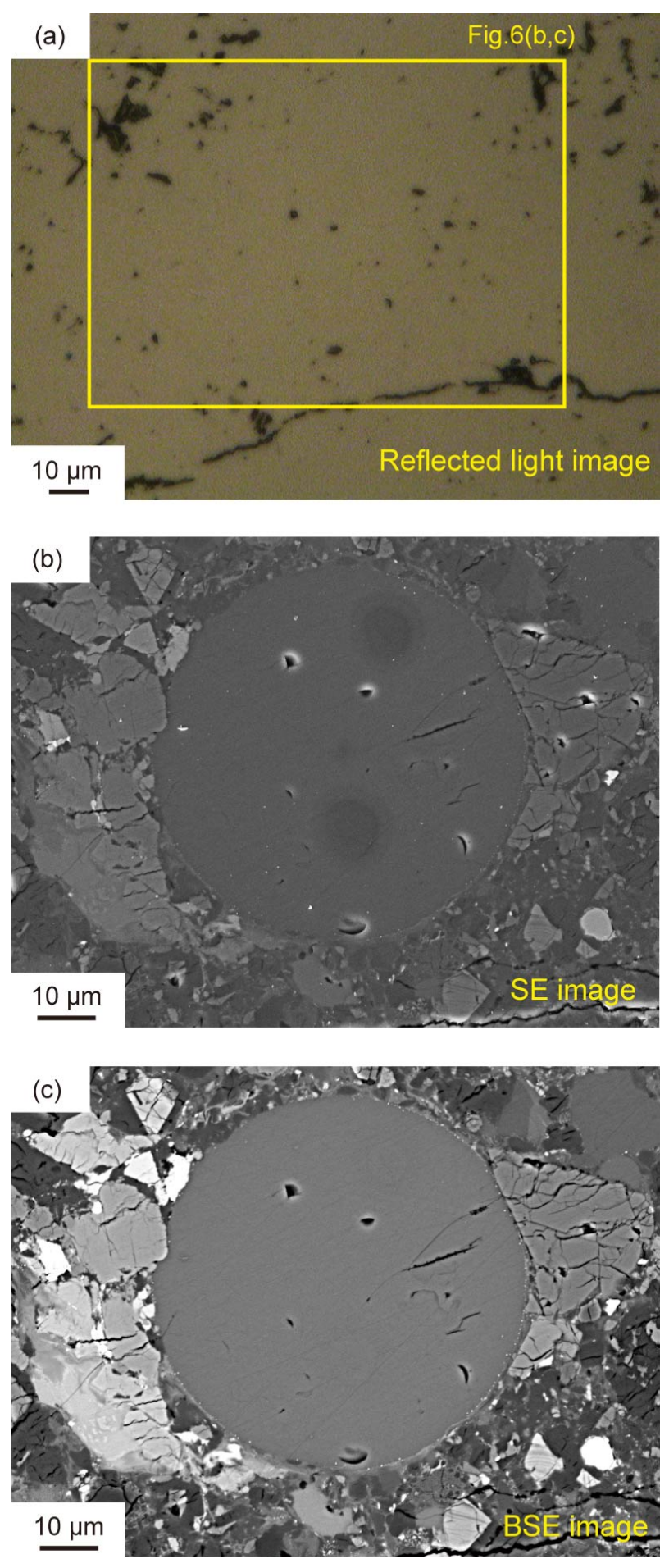

Fig. 6 Surface images of glass sphere in NWA13426 after 10-min electron beam irradiation (beam condition: $20 \mathrm{kV}$ accelerating voltage, $100 \mathrm{nA}$ beam current, $10 \mu \mathrm{m}$ beam diameter). (a) Reflected light image, (b) SE image, and (c) BSE image of a glass sphere in NWA13426 after 10-min irradiation.

positions and optimal background positions. Two key aspects, such as the accurate peak positions and peak overlap corrections for $\mathrm{S}$ and $\mathrm{P}$, were considered here.
S peak shift. With the increased degree of reduced $\mathrm{S}$ content, the $\mathrm{S} K \alpha$ peak $(2 \mathrm{p} \rightarrow 1 \mathrm{~s})$ shifts to higher wavelengths ${ }^{23,28}$ which can be used to calculate the $\mathrm{S}$ oxidation state in glass. ${ }^{28}$ The maximum possible shift could be $\sim 3.0 \AA * 10^{3}$ between $\mathrm{S}^{6+}$ and $\mathrm{S}^{2-}$ whose peak positions could be determined using mineral end-members (e.g., barite and troilite). ${ }^{54}$ Inaccurate peak-position estimation would cause errors in determining the $\mathrm{S}$ contents.

To acquire the peak position of $\mathrm{S} K \alpha$, we performed detailed wavelength scans on each side of the $\mathrm{S}$ peak using the $\mathrm{VG}-2$ glass standard, the Corning B glass standard (NMNH:117218-1), and lunar glass from NWA13426. As shown in Fig. 7a, the S peak shift occurs between the Corning B (S peak: 61015) and VG-2 (S peak: 61040) glass standards, which would result from different sulfur states in the glasses. However, no $\mathrm{S}$ peak shift appears between the VG-2 (S peak: 61040) glass standard and the lunar glass (S peak: 61040). Therefore, the lunar glass and VG-2 glass standard may show similar $\mathrm{S}^{2-} / \mathrm{S}_{\text {total }}$ ratios, further proving that VG-2 glass is an appropriate secondary standard for evaluating the accuracy and precision of $\mathrm{S}$ analysis in lunar glass. Thus, in this study, we selected 61040 as the measured peak position for $\mathrm{S}$.

Peak overlap. Peak intensities can be enhanced by overlapping a neighboring peak, requiring an "overlap correction". ${ }^{36}$ Overlap correction is essential when the peak of a major element overlaps that of a trace element. ${ }^{55}$ The second order $K \beta 1 \mathrm{X}$-ray peak of $\mathrm{Ca}$ commonly co-occurs with the $K \alpha \mathrm{X}$-ray of trace P. To show peak overlap clearly, we ran high-sensitivity wavelength scans on each side of the P peak using the standard GOR128 and VG-2 glasses and diopside. As shown in Fig. 7b, P Ka is interfered by the tail of $\mathrm{Ca} K \beta 1(\mathrm{n}=2)$ peak. This interference can contribute to tens of ppm of $\mathrm{P}$ in diopside $(\mathrm{CaO}=25.72 \mathrm{wt} \%)$. Therefore, we used the peak overlap correction function of the CAMECA software to eliminate the interference. Such peak interference can also be minimized by using a proper pulse height analysis (PHA) setting. ${ }^{19}$ In this study, we also corrected the peak overlap between $\mathrm{Cr}$ and $\mathrm{Mn}$.

Analytical crystals and aggregate counting strategy. Adopting an appropriate diffraction crystal and aggregate intensity counting method is conducive to reducing the detection limits and improving the precision levels. ${ }^{19,56}$ Two spectrometers in our electron microprobe analyzer are equipped with large-area Bragg crystals (LLIF, LPET), covering a $2.5 \times$ collection area relative to standard analyzing crystals. ${ }^{53}$ These large-area Bragg crystals are more suitable for trace element analyses since they have higher sensitivity and higher counting rates than normal area crystals. With the software's aggregate intensity counting capacities, the Xray intensities of different spectrometers can be added together, thus improving the counting rate and the analytical efficiency.

Since the detection limit is in reverse proportion to the square root of the peak-to-background ratio, the net counting rate on the peak position, and the counting time, ${ }^{19}$ it could be lowered by using large-area Bragg crystals and the aggregate intensity 

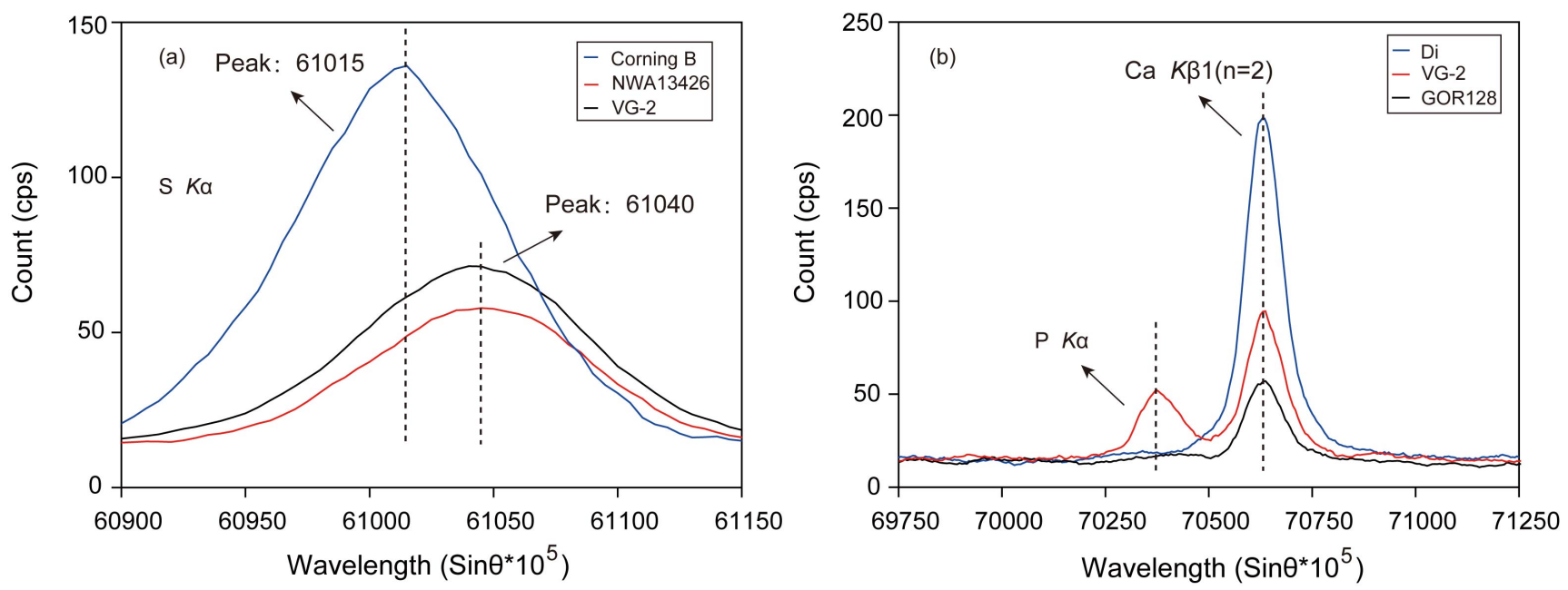

Fig. 7 (a) Smoothed averaged accumulated spectral scans of glass standards (Corning B and VG-2) and lunar glass sphere from NWA13426 at the S K $\alpha$ peak acquired with PET diffraction crystal on CAMECA SXFive microprobe. (b) Smoothed averaged accumulated spectral scans of glass standards (GOR128 and VG-2) and diopside adjacent to P K $\alpha$ peak acquired with LPET diffraction crystal on CAMECA SXFive microprobe. Accelerating voltage $=20 \mathrm{kV}$; beam current $=100 \mathrm{nA}$; beam diameter $=10 \mu \mathrm{m} ;$ dwell time $=500 \mathrm{~ms} ;$ step $=5\left(\operatorname{Sin} \theta^{*} 10^{5}\right)$; accumulation number $=5$.

Table 2. Analytical conditions for lunar glass by EPMA

\begin{tabular}{|c|c|c|c|c|c|c|c|c|}
\hline Element & $\begin{array}{c}\text { Calibration } \\
\text { standard }\end{array}$ & $\begin{array}{c}\text { Beam } \\
\text { current } \\
\text { standard (nA) }\end{array}$ & $\begin{array}{c}\text { Beam current } \\
\text { sample } \\
(\mathbf{n A})\end{array}$ & $\begin{array}{l}\text { Peak counting } \\
\text { time (s) }\end{array}$ & $\begin{array}{c}\text { Background } \\
\text { counting } \\
\text { time }( \pm, s) \\
\end{array}$ & $\begin{array}{l}\text { Analytical } \\
\text { crystals }\end{array}$ & $\begin{array}{c}\text { Bg- }\left(\operatorname{Sin} \theta^{*}\right. \\
\left.10^{5}\right)\end{array}$ & $\begin{array}{c}\mathrm{Bg}+\left(\operatorname{Sin} \theta^{*}\right. \\
\left.10^{5}\right)\end{array}$ \\
\hline $\mathbf{S i}$ & Rhodonite & 10 & 10 & 10 & 10 & TAP & -1500 & 1500 \\
\hline $\mathbf{T i}$ & Pure $\mathrm{TiO}_{2}$ & 10 & 10 & 10 & 10 & LPET & -500 & 500 \\
\hline Al & Pure $\mathrm{Al}_{2} \mathrm{O}_{3}$ & 10 & 10 & 10 & 10 & TAP & -800 & 1000 \\
\hline $\mathrm{Fe}$ & Pure $\mathrm{Fe}_{2} \mathrm{O}_{3}$ & 10 & 10 & 10 & 10 & LLIF & -1000 & 1000 \\
\hline Mg & Pure $\mathrm{MgO}$ & 10 & 10 & 10 & 10 & TAP & -2000 & 2000 \\
\hline Mn & Rhodonite & 10 & 10 & 10 & 10 & LLIF & -800 & 1000 \\
\hline $\mathbf{C a}$ & Diopside & 10 & 10 & 10 & 10 & PET & -600 & 600 \\
\hline $\mathrm{Na}$ & Albite & 10 & 100 & 240 & 240 & $2 \mathrm{TAP}$ & -800 & 800 \\
\hline $\mathbf{K}$ & K-feldspar & 10 & 100 & 120 & 120 & PET+LPET & -700 & 700 \\
\hline $\mathbf{P}$ & Apatite & 10 & 100 & 120 & 120 & LPET & -800 & 1000 \\
\hline $\mathbf{S}$ & Barite & 10 & 100 & 120 & 120 & PET & -600 & 600 \\
\hline $\mathrm{Cr}$ & Pure $\mathrm{Cr}_{2} \mathrm{O}_{3}$ & 10 & 100 & 20 & 20 & LLIF & -1000 & 800 \\
\hline $\mathbf{N i}$ & Pure NiO & 10 & 100 & 240 & 240 & LLIF & -600 & 800 \\
\hline
\end{tabular}

counting method. ${ }^{56}$ Considering the available analytical crystals and spectrometers in the CAMECA SXFive EPMA instrument, the analytical crystal settings used in our developed method were as follows: Two TAP crystals in spectrometers 1 and 4 for Na; a LPET crystal in spectrometer 5 and a PET crystal in spectrometer 2 for K; a LPET crystal in spectrometer 5 for P; a PET crystal in spectrometer 2 for S; and a LLIF crystal in spectrometer 3 for $\mathrm{Cr}$ and Ni. K was analyzed first in spectrometer 2 and 5, followed by $\mathrm{P}$ in spectrometer 5 and $\mathrm{S}$ in spetrometer 2 , respectively.

For the major elements analyzed with a lower beam current (10 $\mathrm{nA}$ ), $\mathrm{Si}$ and $\mathrm{Al}$ were analyzed first in spectrometer 1 and spectrometer 4 using TAP crystal, respectively. $\mathrm{Mg}$ was analyzed in spectrometer 1 following $\mathrm{Si}$. Iron was analyzed first in spectrometer 3 using LLIF crystal, followed by $\mathrm{Mn}$. Ca was analyzed in spectrometer 2 using PET crystal, and Ti was analyzed in spectrometer 5 using LPET crystal.

The detailed analytical settings, including calibration standards, peak/background counting times, background positions, and analytical crystals, are listed in Table 2. Matrix compositional effects were corrected using the CAMECA software X-PHI corrections method. ${ }^{57}$ Oxygen was calculated by cation stoichiometry and included in the matrix correction.

Secondary fluorescence effects. The accuracy of trace elemental analysis in lunar glass would be affected by secondary fluorescence effects from adjacent phases, generated by 
Table 3. Analytical results for trace $\mathrm{Na}, \mathrm{K}, \mathrm{P}, \mathrm{S}, \mathrm{Cr}$, and $\mathrm{Ni}$ in glass standards

\begin{tabular}{|c|c|c|c|c|c|c|c|c|c|c|}
\hline \multirow[b]{3}{*}{ Oxide (wt\%) } & \multicolumn{5}{|c|}{ Optimized method } & \multicolumn{5}{|c|}{ Conventional method } \\
\hline & \multicolumn{2}{|c|}{ GOR128 } & \multicolumn{2}{|c|}{ VG-2 } & \multirow{2}{*}{$\frac{D L}{(3 \sigma)}$} & \multicolumn{2}{|c|}{ GOR128 } & \multicolumn{2}{|c|}{ VG-2 } & \multirow{2}{*}{$\frac{D L}{(3 \sigma)}$} \\
\hline & average & 2 stdev & average & 2 stdev & & average & 2 stdev & average & 2 stdev & \\
\hline $\mathrm{SiO}_{2}$ & 46.50 & 0.21 & 50.56 & 0.21 & & 46.16 & 0.19 & 50.97 & 0.40 & \\
\hline $\mathrm{TiO}_{2}$ & 0.28 & 0.02 & 1.86 & 0.03 & & 0.29 & 0.03 & 1.89 & 0.06 & \\
\hline $\mathbf{A l}_{2} \mathbf{O}_{3}$ & 9.79 & 0.13 & 13.84 & 0.11 & & 9.73 & 0.08 & 13.76 & 0.17 & \\
\hline $\mathrm{Cr}_{2} \mathrm{O}_{3}$ & 0.319 & 0.007 & 0.018 & 0.002 & 0.014 & 0.31 & 0.03 & - & & 0.07 \\
\hline MgO & 25.73 & 0.24 & 6.91 & 0.10 & & 26.07 & 0.15 & 6.79 & 0.15 & \\
\hline $\mathrm{CaO}$ & 6.22 & 0.06 & 10.91 & 0.10 & & 6.16 & 0.07 & 11.04 & 0.05 & \\
\hline MnO & 0.17 & 0.01 & 0.21 & 0.01 & & 0.17 & 0.02 & 0.21 & 0.02 & \\
\hline $\mathrm{FeO}_{(\mathrm{t})}$ & 9.76 & 0.10 & 11.73 & 0.10 & & 9.81 & 0.10 & 11.89 & 0.14 & \\
\hline $\mathrm{NiO}$ & 0.140 & 0.001 & 0.006 & 0.001 & 0.005 & 0.13 & 0.02 & - & & 0.07 \\
\hline $\mathrm{Na}_{2} \mathrm{O}$ & 0.568 & 0.003 & 2.126 & 0.029 & 0.004 & 0.57 & 0.02 & 2.68 & 0.06 & 0.08 \\
\hline $\mathbf{K}_{2} \mathbf{O}$ & 0.034 & 0.001 & 0.189 & 0.001 & 0.002 & - & & 0.19 & 0.02 & 0.04 \\
\hline $\mathbf{P}_{2} \mathbf{O}_{5}$ & 0.027 & 0.002 & 0.200 & 0.005 & 0.010 & - & & 0.20 & 0.03 & 0.12 \\
\hline $\mathrm{SO}_{3}$ & - & & 0.356 & 0.005 & 0.012 & - & & 0.35 & 0.03 & 0.15 \\
\hline Total & 99.53 & 0.36 & 98.90 & 0.29 & & 99.40 & 0.28 & 99.98 & 0.58 & \\
\hline
\end{tabular}

“-": below detection limit; "DL": detection limit.
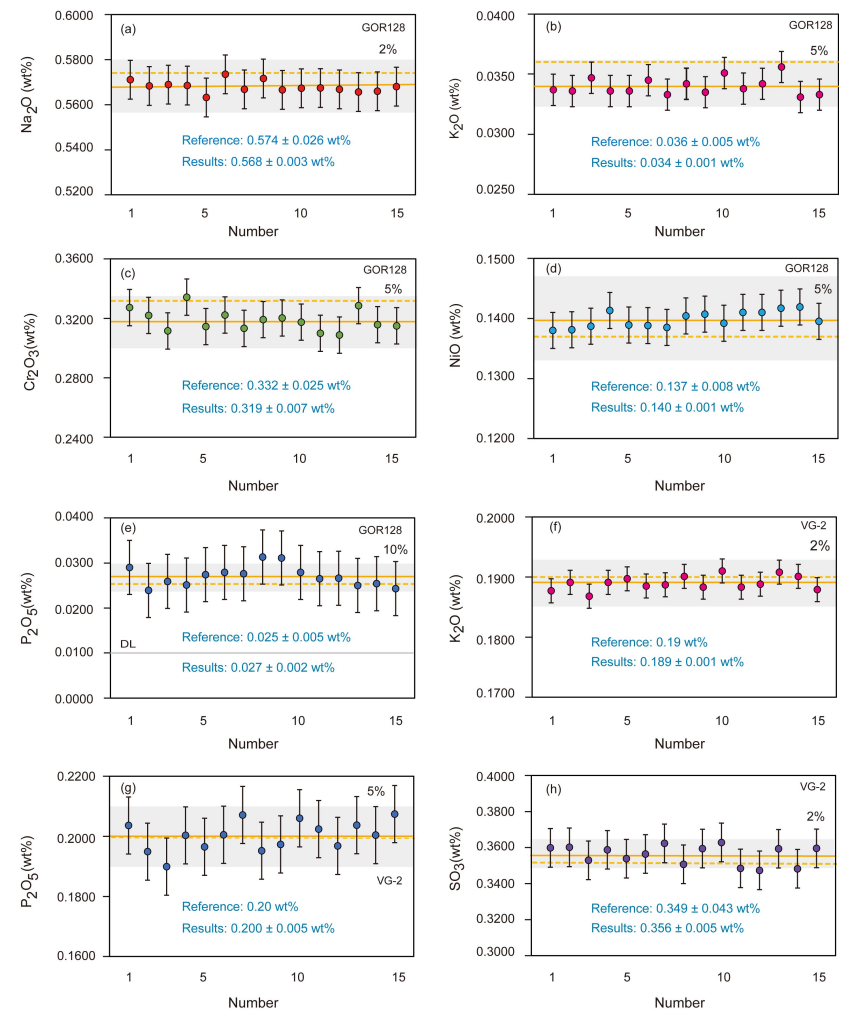

Fig. 8 Fifteen data results on the glass standards for trace $\mathrm{Na}, \mathrm{K}, \mathrm{P}, \mathrm{S}, \mathrm{Cr}$, and $\mathrm{Ni}$ (oxide, wt $\%$ ). The shaded portion represents the $2 \%-10 \%$ margin of error. The dotted line represents the recommended value, and the solid line represents the average value. Error bars $=2$ standard deviations. characteristic and bremsstrahlung X-ray emissions during electron-specimen interactions. The primary X-rays penetrate the specimen in all directions and can further ionize atoms at distances over several tens to hundreds of microns. ${ }^{58-60}$ As a result, contributions from secondary fluorescence in adjacent phases rich in $\mathrm{Na}, \mathrm{K}, \mathrm{P}, \mathrm{S}, \mathrm{Cr}$, and $\mathrm{Ni}$ would potentially increase the trace element contents measured in lunar glass.

Secondary fluorescence effects can be minimized by selecting the analyzed positions away from the phases with considerable $\mathrm{Na}$, $\mathrm{K}, \mathrm{P}, \mathrm{S}, \mathrm{Cr}$, and $\mathrm{Ni}$ contents. In addition, secondary fluorescence effects can be corrected using additional software with an appropriate geometry model, such as the FANAL computer code in CalcZAF/Standard software. ${ }^{59,60}$ In most cases, lunar glass samples are separated from lunar soil and are mounted in epoxy resin or indium for further analysis. Therefore, secondary fluorescence effects do not play a role in such situations. However, glass spheres in meteorites are commonly surrounded by plagioclase and pyroxene. Appropriate geometry models must be set up to correct or evaluate secondary fluorescence effects, which will be tested in the following section.

\section{DETECTION LIMIT, PRECISION, AND ACCURACY OF TRACE ELEMENTS IN GLASS}

To evaluate the analytical method's detection limit, precision, and accuracy, we ran the GOR128 and VG-2 glass standards as 
unknown samples. The analytical results are listed in Table 3 and Table S1. The detection limits $(3 \sigma)$ were calculated by CAMECA software based on the equation suggested by Ancey et al. ${ }^{61}$ In our developed method, the detection limits $(3 \sigma)$ for $\mathrm{Na}, \mathrm{K}, \mathrm{P}, \mathrm{S}, \mathrm{Cr}$, and $\mathrm{Ni}$ in glass are $29,17,45,46,96$, and $35 \mathrm{ppm}$, respectively. The detection limits $(3 \sigma)$ for the corresponding elemental oxide are 0.004 wt $\%\left(\mathrm{Na}_{2} \mathrm{O}\right), 0.002 \mathrm{wt} \%\left(\mathrm{~K}_{2} \mathrm{O}\right), 0.010 \mathrm{wt} \%\left(\mathrm{P}_{2} \mathrm{O}_{5}\right), 0.012$ $\mathrm{wt} \%\left(\mathrm{SO}_{3}\right), 0.014 \mathrm{wt} \%\left(\mathrm{Cr}_{2} \mathrm{O}_{3}\right)$ and $0.005 \mathrm{wt} \%(\mathrm{NiO})$, respectively. Almost all $\mathrm{Na}, \mathrm{K}, \mathrm{P}, \mathrm{S}, \mathrm{Cr}$, and $\mathrm{Ni}$ analytical results in the two glass standards are above the detection limits (Table S1).

The analytical precision (reproducibility) established by 15 repeated measurements of the glass standards is $0.001 \mathrm{wt} \%$ to $0.007 \mathrm{wt} \%$ for trace element oxides (Table 3, 2SDs). At elemental oxide concentration levels higher than $0.1 \mathrm{wt} \%$ (Fig. 8), the analytical results vary within $\pm 5 \%$. For example, the analytical results of $\mathrm{Na}_{2} \mathrm{O}$ in the GOR128 glass standard merely fluctuate within $\pm 2 \%$. At elemental oxide concentration levels below 0.1 $\mathrm{wt} \%$, the results vary within nearly $\pm 10 \%$, such as the $5 \%$ variation range for $\mathrm{K}_{2} \mathrm{O}$ results in the GOR128 glass standard.

The accuracy was tested by comparing the analyses of the glass standards with reference data. As shown in Fig. 8, the average values of the 15 analyses for the trace elements of interest in the
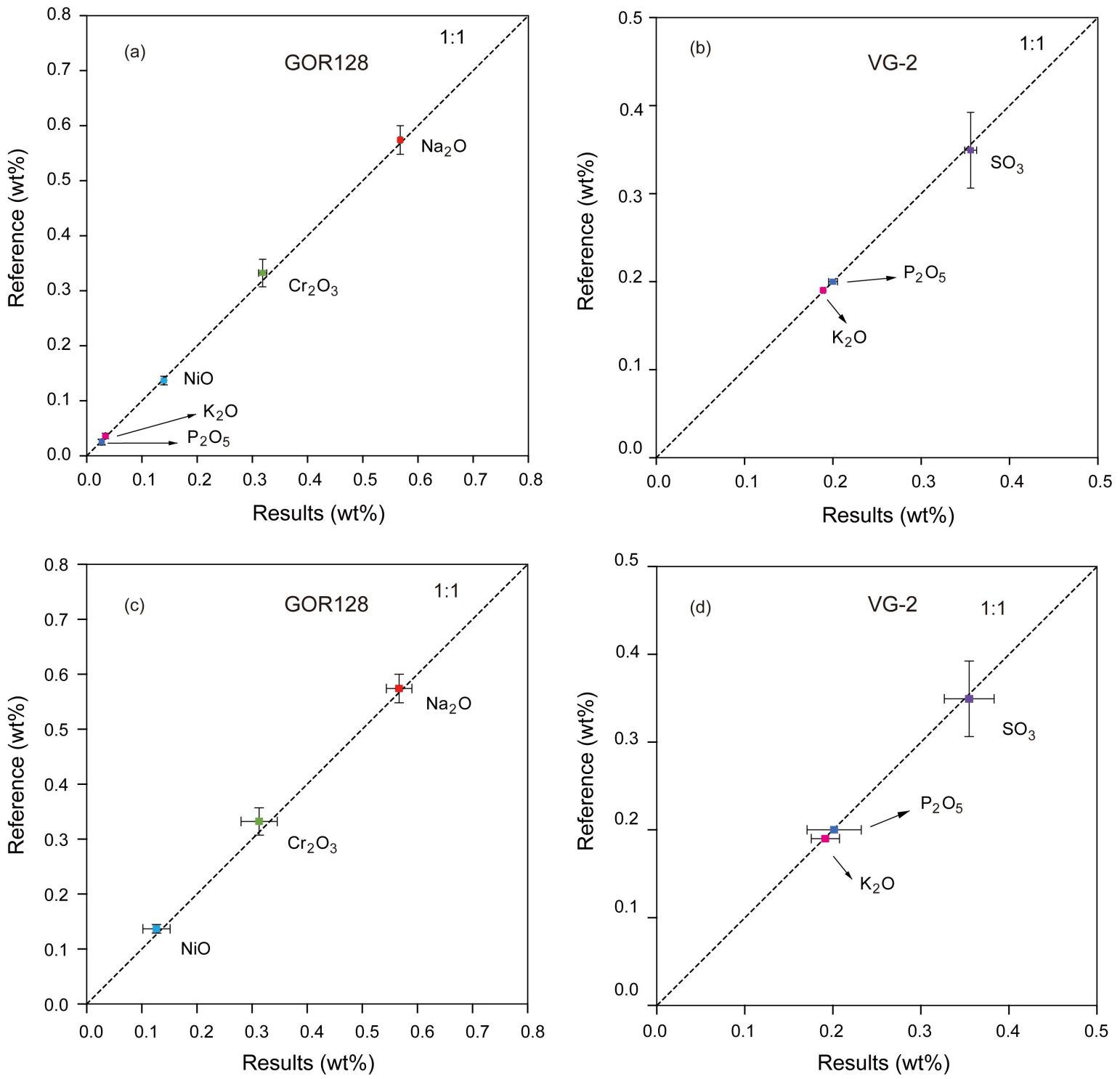

Fig. 9 Comparison of trace $\mathrm{Na}, \mathrm{K}, \mathrm{P}, \mathrm{Cr}$, and $\mathrm{Ni}$ contents (oxide, wt $\%$ ) in GOR128 glass standard (a) and trace K, P, and S contents (oxide, wt $\%$ ) in VG-2 glass standard (b) obtained by optimized EPMA method with reference data. Comparison of trace $\mathrm{Na}, \mathrm{Cr}$, and Ni contents (oxide, wt $\%$ ) in GOR128 glass standard (c) and trace K, P, and S contents (oxide, wt \%) in VG-2 glass standard (d) obtained by conventional EPMA method with reference data. (Error bar=2 $\mathrm{sd})$. 
glass standards are consistent with the reference values within error. For example, 15 measurements of the GOR128 glass standard give the $\mathrm{Na}_{2} \mathrm{O}$ average value of $0.568 \pm 0.003 \mathrm{wt} \%$, showing good agreement with the recommended value $(0.574 \pm$ $0.026 \mathrm{wt} \%$ ). The average values of 15 analyses for $\mathrm{K}_{2} \mathrm{O}$ in GOR128 glass standard and VG-2 glass standard are $0.034 \pm$ $0.001 \mathrm{wt} \%$ and $0.189 \pm 0.001 \mathrm{wt} \%$, respectively, which are in good agreement with the recommended values $(0.036 \pm 0.005 \mathrm{wt} \%$ for GOR128 glass standard, $0.19 \mathrm{wt} \%$ for VG-2 glass standard). All data plot well along the 1:1 correspondence line within the precision of methods (Fig. 9a and 9b).

It is worth noting that the average value of 15 analyses for $\mathrm{Na}_{2} \mathrm{O}$ in the VG-2 glass standard $(2.126 \pm 0.029 \mathrm{wt} \%)$ is lower than the recommended value $(2.62 \mathrm{wt} \%$ ) due to the apparent reduction of $\mathrm{Na} K \alpha \mathrm{X}$-ray in VG-2 glass at a high beam current (Fig. S2). However, K Ka X-ray remains steady over 600 s electron beam bombardment at the optimal beam condition. Therefore, this beam condition is unsuitable for analyzing $\mathrm{Na}$ in basaltic glass with a $\mathrm{Na}_{2} \mathrm{O}$ content higher than $2 \mathrm{wt} \%$.

\section{COMPARISON TO ANALYTICAL RESULTS BY THE CONVENTIONAL METHOD}

To better reveal the advantages of the optimized method, we compared the results of the optimized method with those obtained by the conventional method (often used for routine glass analysis). For the conventional method, beam current and peak counting time are $10 \mathrm{nA}$ and $10 \mathrm{~s}$, respectively. Sodium, potassium, and silicon were analyzed first, and each element was only analyzed by one spectrometer. Other analytical conditions, such as accelerating voltage, peak/background positions, and calibration standards, are identical to those of the optimized method. Ten measurement points on the glass standards were conducted to evaluate the conventional analytical method's detection limit, precision, and accuracy. The analytical results are listed in Table 3 and Table S2.

Using the conventional method, the detection limits $(3 \sigma)$ for the trace elements in the GOR128 glass standard are 351 to $613 \mathrm{ppm}$. The detection limits for corresponding elemental oxides are 0.08 wt $\%\left(\mathrm{Na}_{2} \mathrm{O}\right), 0.04 \mathrm{wt} \%\left(\mathrm{~K}_{2} \mathrm{O}\right), 0.12 \mathrm{wt} \%\left(\mathrm{P}_{2} \mathrm{O}_{5}\right), 0.15 \mathrm{wt} \%\left(\mathrm{SO}_{3}\right)$, $0.07 \mathrm{wt} \%\left(\mathrm{Cr}_{2} \mathrm{O}_{3}\right)$, and $0.07 \mathrm{wt} \%(\mathrm{NiO})$, respectively, which are one order of magnitude higher than those of the optimized method. The $\mathrm{K}$ and $\mathrm{P}$ contents in GOR128 glass standard are below the detection limit. The precision of the conventional method (reproducibility) is $0.02-0.03 \mathrm{wt} \%$ for trace elemental oxides (2 standard deviations, Table 3), which are nearly two orders of magnitude higher than the optimized method. The average values of the 10 analyses for minor/trace $\mathrm{Na}, \mathrm{K}, \mathrm{P}, \mathrm{S}, \mathrm{Cr}$, and $\mathrm{Ni}$ in the glass standards are consistent with the reference values within error (Table 3). All data plot well along the 1:1 correspondence line within the precision of methods (Fig. 9c and 9d), suggesting that the conventional way shows the same accuracy as the optimized method.

In summary, the optimized method could provide identical accuracy for minor/trace $\mathrm{Na}, \mathrm{K}, \mathrm{P}, \mathrm{S}, \mathrm{Cr}$, and $\mathrm{Ni}$ analysis in lunar glass to the conventional method, but with an apparent lower detection limit and higher precision.
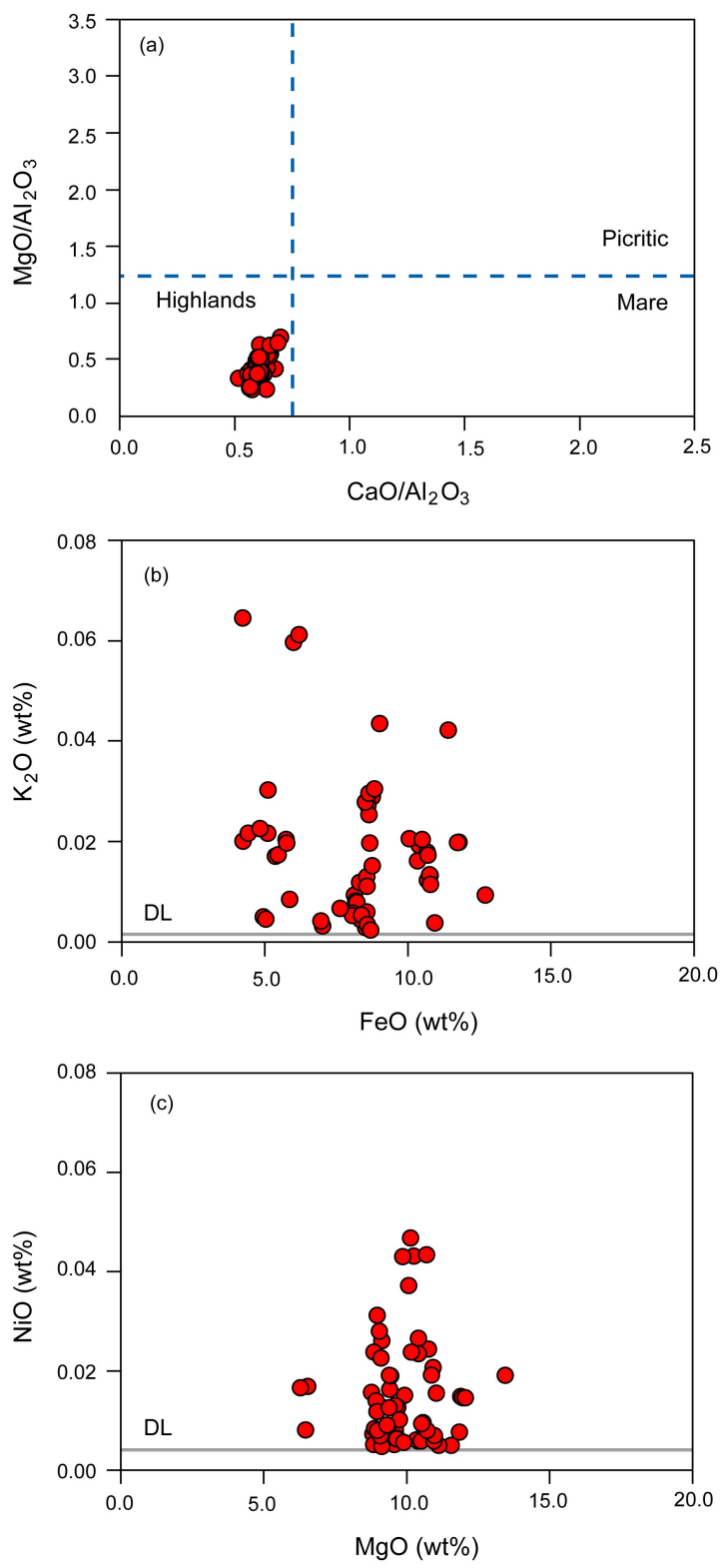

Fig. 10 Chemical characteristics of the studied lunar glass spheres from NWA13426. (a) Major element ratios $\mathrm{CaO} / \mathrm{Al}_{2} \mathrm{O}_{3}$ and $\mathrm{MgO} / \mathrm{Al}_{2} \mathrm{O}_{3}$ of the studied lunar glass spheres. Dividing lines at $\mathrm{CaO} / \mathrm{Al}_{2} \mathrm{O}_{3}=0.75^{2}$ and $\mathrm{MgO} / \mathrm{Al}_{2} \mathrm{O}_{3}=1.25^{1}$ are shown. (b) $\mathrm{FeO}$ and $\mathrm{K}_{2} \mathrm{O}$ compositions of the studied lunar glass spheres. $\mathrm{K}_{2} \mathrm{O}$ contents in studied lunar glass spheres are apparently below $0.15 \mathrm{wt} \%$, pointing to the affinity of highland-mare mixed glass. (c) The abundance of $\mathrm{NiO}$ and $\mathrm{MgO}$ has no correlation in the studied lunar glass spheres. 


\section{APPLICATIONS TO LUNAR GLASS}

In lunar glass, the trace-levels of $\mathrm{Na}, \mathrm{K}, \mathrm{P}, \mathrm{S}, \mathrm{Cr}$, and $\mathrm{Ni}$ are essential to understanding the glass types, impact volatilization, and magmatic revolution processes. ${ }^{2,3,13}$ Here we apply our new method to the lunar glass spheres of NWA13426, a regolith breccia meteorite. Since plagioclase in the NWA13426 meteorite is anorthite with only a small amount of $\mathrm{Na}$ (Table S3), the secondary fluorescence effect of $\mathrm{Na}$ caused by the adjacent anorthite might be very limited. To test this idea, we used the computer code FANAL of the CalcZAF/Standard software. As shown in Fig. S3, the secondary fluorescence effect of $\mathrm{Na}$ by adjacent anorthite can be neglected when choosing the analytical position of $>20 \mu \mathrm{m}$ to the boundary. Since the studied lunar glass spheres are not in contact with $\mathrm{K}$-feldspar, apatite, troilite, Cr-spinel, and Fe-Ni metals, the secondary fluorescence effects for trace K, P, S, Cr, and $\mathrm{Ni}$ analysis can be ignored. Representative compositions of the studied lunar glass spheres are listed in Table S4.

The glass spheres in NWA13426 show compositional heterogeneity among different grains and have relatively wide ranges of $\mathrm{SiO}_{2}(33.73-48.54 \mathrm{wt} \%), \mathrm{Al}_{2} \mathrm{O}_{3}(16.53-30.77 \mathrm{wt} \%), \mathrm{CaO}$ (11.38-17.94 wt\%), $\mathrm{MgO}(6.27-13.45 \mathrm{wt} \%)$, and $\mathrm{FeO}(\mathrm{t})(4.23-$ $12.71 \mathrm{wt} \%)$. They have low $\mathrm{CaO} / \mathrm{Al}_{2} \mathrm{O}_{3} \quad(0.52-0.70)$ and $\mathrm{MgO} / \mathrm{Al}_{2} \mathrm{O}_{3}$ ratios (0.24-0.70), likely pointing to a highland origin (Fig. 10a). However, this plot relying on major elements cannot distinguish some highland-mare mixed glasses and incompatible trace element (ITE)-rich glasses ${ }^{2}$ because the ITE-rich ones also have a $\mathrm{CaO} / \mathrm{Al}_{2} \mathrm{O}_{3}$ ratio between 0.60 and 0.75 . Therefore, other indicators are needed to discriminate glass type. The ITE-rich glass commonly has a $\mathrm{K}_{2} \mathrm{O}$ content higher than $0.15 \mathrm{wt} \%{ }^{2}$, contrary to the studied glass spheres with only trace-level $\mathrm{K}_{2} \mathrm{O}$ (0.003-0.065 wt\%) (Fig. 10b). In addition, the NiO contents of volcanic glass exhibit a clear linear relationship with the $\mathrm{MgO}$ contents. ${ }^{5}$ However, there is no clear correlation between the $\mathrm{MgO}$ and $\mathrm{NiO}$ contents in the studied glass (Fig. 10c), implying an impact origin. Therefore, the studied glass spheres in NWA13426 are typical highland impact glasses, which is also supported by the petrographic characteristics. Our developed method can provide critical compositional constraints on lunar samples.

\section{CONCLUSIONS}

An optimized analytical method for high-precision measurement of trace $\mathrm{Na}, \mathrm{K}, \mathrm{P}, \mathrm{S}, \mathrm{Cr}$, and $\mathrm{Ni}$ in lunar glass, simultaneously with major elements, was developed using the CAMECA SXFive EPMA. The optimal analytical conditions used for the trace elements of interest in lunar glass were as follows: accelerating voltage of $20 \mathrm{kV}$, beam current of $100 \mathrm{nA}, 10 \mu \mathrm{m}$ beam diameter, linear background mode, accurate peak determination of $\mathrm{S}(K \alpha)$, and using the large-area analytical crystal and aggregate counting strategy. Replicate analyses on glass standards using the proposed optimized method show identical accuracy with the conventional method but with higher precision and lower detection limit. This optimized method can fully exert the advantages of nondestructive nature, high spatial resolution, and high precision and accuracy of EPMA. Our method would open a new perspective into the study of geochemical processes involving lunar glass.

\section{ASSOCIATED CONTENT}

The supporting information (Figs S1-S3; Tables S1-S4) is available at www.at-spectrosc.com/as/home

\section{AUTHOR INFORMATION}

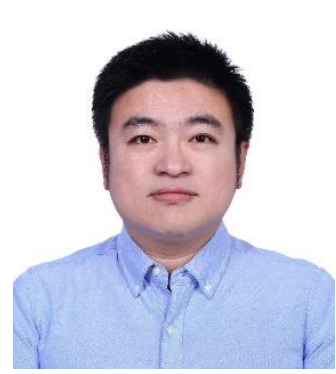

Yi Chen is a research professor of geology at the Institute of Geology and Geophysics, Chinese Academy of Sciences (IGGCAS) in Beijing, China. He received his B.S. degree in Geology from China University of Geosciences (Wuhan) in 2003, and completed Ph.D. in petrology from the IGGCAS in 2008 . He worked as a postdoctoral research fellow from 2008 to 2010 at the IGGCAS. His early research focused on thermodynamic modeling and high-grade metamorphism. His recent research interests have expanded to subduction zone crust-mantle interactions, subduction zone geodynamics, planetary materials, highprecision EPMA microanalyses and their applications to Earth and Planetary science. Currently, he is on the editorial board for Frontiers in Earth Science, and also on the committee of Metamorphic Petrology in the Chinese Society for Mineralogy, Petrology and Geochemistry, and the committee of Petrology in Geological Society of China. He has published over 60 peer-reviewed scientific papers in ISI-indexed journals.

\section{Corresponding Author}

*Y. Chen

Email address: chenyi@mail.iggcas.ac.cn

Notes

The authors declare no competing financial interest.

\section{ACKNOWLEDGMENTS}

This study was supported by the Key Research Program of the Chinese Academy of Sciences (ZDBS-SSW-JSC007-15), the pre-research project on Civil Aerospace Technologies of China National Space Administration (D020203), the Key Research Program (IGGCAS-202101), and the Experimental Technology Innovation Fund (11990890) of the Institute of Geology and Geophysics, Chinese Academy of Sciences. Critical reviews 
by two anonymous reviewers and editorial work by Jin-Hua $\mathrm{Li}$ and Anneliese Lust helped to improve the manuscript.

\section{REFERENCES}

1. J. W. Delano, J. Geophys. Res-Sol. Ea., 1986, 91, 201-213. https://doi.org/10.1029/JB091iB04p0D201

2. R. A. Zeigler, R. L. Korotev, B. L. Jolliff, L. A. Haskin, and C. Floss, Geochim. Cosmochim. Acta, 2006, 70, 6050-6067. https://doi.org/10.1016/j.gca.2006.08.040

3. N. E. B. Zellner, J. Geophys Res-Planets, 2019, 124, 2686-2702. https://doi.org/10.1029/2019JE006050

4. S. Taylor and P. Jakes, Geochimica et Cosmochimica Acta, 1974, 2 , 1287-1305. https://hdl.handle.net/20.500.11753/1611

5. J. W. Delano and K. Livi, Geochim, Cosmochim. Acta, 1981, 45, 2137-2149. https://doi.org/10.1016/0016-7037(81)90066-1

6. A. E. Saal, E. H. Hauri, M. L. Cascio, J. A. Van Orman, M. C. Rutherford, and R.F. Cooper, Nature, 2008, 454. 192-195. https://doi.org/10.1038/nature07047

7. A. E. Saal and E. H. Hauri, Sci. Adv, 2021, 7, eabe4641. https://doi.org/10.1126/sciadv.abe4641

8. E. Chao, J. A. Boreman, J. A. Minkin, O. B. James, and G.A. Desborough, J. Geophys. Res., 1970, 75, 7445-7479. https://doi.org/10.1029/JB075i035p07445

9. J. W. Delano, N. E. B. Zellner, F. Barra, E. Olson, T.D. Swindle, N. J. Tibbetts, and D. C. B. Whittet, Meteorit. Planet. Sci., 2007, 42, 993-1004. https://doi.org/10.1111/j.1945-5100.2007.tb01146.x

10. R. L. Korotev, R. A. Zeigler, and C. Floss, Geochim. Cosmochim. Acta, 2010, 74, 7362-7388. https://doi.org/10.1016/j.gca.2010.09.020

11. C. K. Shearer, J. J. Papike, K. C. Galbreath, S. J. Wentworth, and N. Shimizu, Geochim. Cosmochim. Acta, 1990, 54, 1851-1857. https://doi.org/10.1016/0016-7037(90)90418-K

12. M. Norman, M. J. Drake, and J. H. Jones, Lunar Planet. SCI.,1994, 25, 1009-1010.

13. J. W. Delano, Lunar Planet. Sci.,1996, 303-304.

14. E. C. Mcintosh, M. Porrachia, F. M. Mccubbin, and J. Day, Lunar and Planetary Science Conference, 2017.

15. J. F. Lovering and N.G. Ware, Geochim. Cosmochim. Acta, 1970, 1, 633-654. https://doi/10.1016/S0016-7037(97)00285-8

16. J. W. Delano, Geochim Cosmochim Acta, 1991, 55, 3019-3029. https://doi/10.1016/0016-7037(91)90470-P

17. J. W. Delano, B. Z. Hanson, and E. B. Watson, Proceedings of the 25th Lunar and Planetary Science Conference, 1994, 325-326.

18. N. E. B. Zellner, P. D. Spudis, J. W. Delano, and D. C. B. Whittet, J. Geophys. Res.-Planets, 2002, 107, 12-1-12-13. https://doi.org/10.1029/2001JE001800

19. V. G. Batanova, A.V. Sobolev, and D.V. Kuzmin, Chem. Geol., 2015, 419, 149-157. https://doi.org/10.1016/j.chemgeo.2015.10.042

20. C. Zhang, J. Koepke, L.-X. Wang, P. E. Wolff, S. Wilke, A. Stechern, R. Almeev, and F. Holtz, Geostand. Geoanal. Res., 2016, 40, 351-363. https://doi.org/10.1111/j.1751-908X.2015.00390.x

21. C. Zhang, R. R. Almeev, E. C. Hughes, A. A. Borisov, E. P. Wolff, H. E. Höfer, R. E. Botcharnikov, and J. Koepke, Am. Mineral., 2018, 103, 1445-1454. https://doi.org/10.2138/am-2018-6437

22. J. Q. Cui, S. Y. Yang, S. Y. Jiang, and J. Xie, Microsc. Microanal., 2019, 25, 47-57. https://doi.org/10.1017/S1431927618015672
23. E. C. Hughes, B. Buse, S. L. Kearns, R. A. Brooker, D. Di Genova, G. Kilgour, H. M. Mader, and J. D. Blundy, IOP Conference Series: Materials Science and Engineering, 2020, 891, 012014. https://doi.org/10.1088/1757-899x/891/1/012014

24. A. Kronz, A. M. Van den Kerkhof, and A. Müller, Quartz: Deposits, Mineralogy and Analytics, 2012. 191-217. https://doi.org/10.1007/978-3-642-22161-3_9

25. G. B. Morgan and D. London, Am. Mineral., 1996, 81, 1176-1185. https://doi.org/10.2138/am-1996-9-1016

26. G. B. Morgan, and D. London, Am. Mineral., 2005, 90, 1131-1138. https://doi.org/10.2138/am.2005.1769

27. C. Hayward, Holocene, 2011, 22, 119-125. https://doi.org/10.1177/0959683611409777

28. M. R. Carroll and M. J. Rutherford, Am. Mineral., 1988, 73, 845849.

29. K. P. Jochum, B. Stoll, K. Herwig, M. Willbold, A. W. Hofmann, M. Amini, S. Aarburg, W. Abouchami, E. Hellebrand, B. Mocek, I. Raczek, A. Stracke, O. Alard, C. Bouman, S. Becker, M. Dücking, H. Brätz, R. Klemd, D. de Bruin, D. Canil, D. Cornell, C. J. de Hoog, C. Dalpé, L. Danyushevsky, A. Eisenhauer, Y. Gao, J. E. Snow, N. Groschopf, D. Günther, C. Latkoczy, M. Guillong, E. H. Hauri, H. E. Höfer, Y. Lahaye, K. Horz, D. E. Jacob, S. A. Kasemann, A. J. R. Kent, T. Ludwig, T. Zack, P. R. D. Mason, A. Meixner, M. Rosner, K. Misawa, B. P. Nash, J. Pfänder, W. R. Premo, W. D. Sun, M. Tiepolo, R. Vannucci, T. Vennemann, D. Wayne, and J. D. Woodhead, Geochem. Geophys. Geosy., 2006, 7. Q02008, https://doi.org/10.1029/2005gc001060

30. E. Jarosewich, Nelen, J. A., and Norberg, J. A., Geostandards Newsletter, 1980, 4, 43-47. https://doi.org/10.1111/j.1751-908X.1980.tb00273.x

31. R. T. Helz, D. A. Clague, L. G. Mastin, and T. R Rose, 2014. https://doi.org/10.3133/ofr20141090

32. R. J. D'Souza and D. Canil, Am. Mineral., 2018, 103, 1030-1043. https://doi.org/10.2138/am-2018-6404

33. N. Metrich, J. L. Joron, and B. Berthier, Geochim. Cosmochim. Acta, 1998, 62, 507-514. https://doi.org/10.1016/S0016-7037(97)00365-7

34. J. C. M. de Hoog, P. R. D. Marson, and M. J. van Bergen, Geochim. Cosmochim. Acta, 2001, 65, 3147-3164. https://doi.org/10.1016/S0016-7037(01)00634-2

35. M. J. Stock, M. C. S. Humphreys, V. C. Smith, R. D. Johnson, D. M. Pyle, and EIMF, Am. Mineral., 2014, 100, 281-293. https://doi.org/10.2138/am-2015-4949

36. S. J. B. Reed, Cambridge University Press, 2005. https://doi.org/10.1017/CBO9780511610561

37. L. Cheng, C. Zhang, X. Li, R. R. Almeev, X. Yang, and F. Holtz, Microsc Microanal, 2019, 25, 874-882. https://doi.org/10.1017/S1431927619014612

38. W. L. Zhang, X. D. Che, R. C. Wang, L. Xie, X. F. Li, D. Zhang, Chinese Sci. Bull., 2020, 65, 3205-3216. https://doi.org/10.1360/tb-2020-0316

39. R. Q. Wu, C. Rao, Q. Wang, D. Zhang, Chinese Sci. Bull., 2020, 65, 2161-2168. https://doi.org/10.1360/tb-2020-0082

40. B. Su, Y. Chen, Q. Mao, D. Zhang, L.-H. Jia, and S. Guo, Lithos, 2019, 344-345, 207-216. https://doi.org/10.1016/j.lithos.2019.06.029

41. X. Llovet, A. Moy, P. T. Pinard, and J. H. Fournelle, Prog. Mater. Sci., 2021, 116, 100673. https://doi.org/10.1016/j.pmatsci.2020.100673 
42. D. Drouin, A. C. Couture, D. Joly, X. Tastet, V. Aimez, R. Gauvin, Scanning, 2007, 29, 92-101. https://doi.org/10.1007/s00339-0169939-4

43. S. J. Lane and J. A. Dalton, Am. Mineral., 1994, 79, 745-749.

44. X. Zhang, S. Y. Yang, H. Zhao, S. Y. Jiang, R. X. Zhang, and J. Xie, J. Earth Syst. Sci., 2017, 30, 834-842. https://doi.org/10.1007/s12583-017-0939-x

45. M. A. W. Marks, T. Wenzel, M. J. Whitehouse, M. Loose, T. Zack, M. Barth, L. Worgard, V. Krasz, G. N. Eby, H. Stosnach, and G. Markl, Chem. Geol., 2012, 291, 241-255. https://doi.org/10.1016/j.chemgeo.2011.10.026

46. M. C. S. Humphreys, S. L. Kearns, and J. D. Blundy, Am. Mineral., 2006, 91, 667-679. https://doi.org/10.2138/am.2006.1936

47. K. Jurek and O. Gedeon, Spectrochim. Acta B, 2003, 58, 741-744. https://doi.org/10.1016/S0584-8547(02)00288-4

48. J. G. Spray, and D. A. Rae, Can. Mineral., 1995, 33. 323-332.

49. S. Kearns, B. Buse, and J. Wade, Microsc. Microanal., 2014, 20, 740-741. https://doi.org/10.1017/s143192761400542x

50. S. L. Kearns and B. Buse, Microsc. Microanal., 2016, 22, 416-417. https://doi.org/10.1017/s1431927616002932

51. C. H. Nielsen and H. Sigurdsson, Am. Mineral., 1981, 66, 547-552.
52. S. L. Kearns, N. Steen, and E. Erlund, Microsc. Microanal., 2002, 8, S02, 1562-1563. https://doi.org/10.1017/S1431927602107562

53. M. J. Jercinovic, M. L. Williams, and E. D. Lane, Chem. Geol., 2008, 254, 197-215. https://doi.org/10.1016/j.chemgeo.2008.05.016

54. M. C. Rowe, A. J. R. Kent, and R. L. Nielsen, Chem. Geol., 2007, 236, 303-322. https://doi.org/10.1016/j.chemgeo.2006.10.007

55. J. I. Goldstein, Scanning Electron Microscopy and X-ray Microanalysis, 2007.

56. J. J. Donovan, H. A. Lowers, and B. G. Rusk, Am. Mineral., 2011, 96, 274-282. https://doi.org/10.2138/am.2011.3631

57. C. Merlet, Microchim. Acta, 1994, 114/115, 363-376.

57. J. H. Fournelle, S. Kim, and J. H. Perepezko, Surf. Interface Anal., 2005, 37, 1012-1016. https://doi.org/10.1002/sia.2114

59. X. Llovet, P. T. Pinard, J. J. Donovan, F. Salvat. J. Phys. D. Appl. Phys., 2012. 45, 225301. https://doi.org/10.1088/0022-3727/45/22/225301

60. A. Y. Borisova, N. R. Zagrtdenov, M. J. Toplis, J. J. Donovan, X. Llovet, P. D. Asimow, P. Parseval, and S. Gouy, Chem. Geol., 2018, 490, 22-29. https://doi.org/10.1016/j.chemgeo.2018.05.010

61. M. Ancey, F. Bastenaire, and R. Tixier, J. Phys. D: Appl Phys., 1978, 10, 319-343. https://doi.org/10.1088/0022-3727/10/6/004 